\title{
Male partner attendance of skilled antenatal care in peri-urban Gulu district, Northern Uganda
}

\author{
Raymond Tweheyo ${ }^{1 *}$, Joseph Konde-Lule ${ }^{2}$, Nazarius M Tumwesigye ${ }^{2}$, Juliet N Sekandi ${ }^{2}$
}

\begin{abstract}
Background: Male partner attendance of skilled Antenatal Care (ANC) is beneficial to improving maternal outcomes. This study investigated the level, perceived benefits and factors associated with male partner attendance of skilled ANC in a peri-urban community recovering from two decades of civil conflict.
\end{abstract}

Methods: This cross-sectional survey used multi-stage sampling in 12 villages of Omoro county to select 331 married male respondents aged 18 years or more, whose female spouses had childbirth within 24 months prior to the survey. A structured questionnaire elicited responses about male partner attendance of ANC during pregnancy at a public health facility as the main outcome variable. Analysis used Generalized Linear Model (GLM) in Stata version 10.0 to obtain Prevalence Risk Ratios (PRR) for association between the binary outcome and independent factors. All factors significant at $p<0.15$ and potential confounders were included in the multivariable model.

Results: Overall, $65.4 \%(95 \% \mathrm{Cl} ; 60.3,70.5)$ male partners attended at least one skilled ANC visit. Mean age was 31.9 years [SD 8.2]. Perceived benefits of attending ANC were: HIV screening (74.5\%), monitoring foetal growth (34\%) and identifying complications during pregnancy (18.9\%). Factors independently associated with higher ANC attendance were: knowledge of 3 or more ANC services (adj.PRR 2.77; 95\%Cl 2.24, 3.42), obtaining health information from facility health workers (adj.PRR 1.14; 95\%Cl 1.01, 1.29) and if spouse had skilled attendance at last childbirth (adj.PRR 1.31; 95\% Cl 1.04-1.64). However, factors for low attendance were: male partners intending their spouse to carry another pregnancy (adj.PRR 0.83; $95 \% \mathrm{Cl} 0.71,0.97$ ) and living more than $5 \mathrm{Km}$ from a health facility (adj.PRR 0.83, 95\% Cl 0.70, 0.98).

Conclusions: Men who were knowledgeable of ANC services, obtained health information from a health worker and whose spouses utilised skilled delivery at last pregnancy were more likely to accompany their spouses at ANC, unlike those who wanted to have more children and lived more than $5 \mathrm{~km}$ from the health facility. These findings suggest that empowering male partners with knowledge about ANC services may increase their ANC participation and in turn increase skilled delivery. This strategy may improve maternal health care in post conflict and resourcelimited settings.

\section{Background}

Worldwide, male attendance of skilled ANC and delivery care remains a challenge to safe motherhood. About 210 million women become pregnant each year with 30 million (15\%) developing complications, resulting into over half a million maternal deaths [1]. Developing countries account for more than $99 \%$ of all maternal deaths; about a half occurring in sub-Saharan Africa, and a third in South Asia $[2,3]$. There is slow progress towards achieving the fifth

\footnotetext{
* Correspondence: ratweheyo@yahoo.co.uk

${ }^{1}$ Makerere University School of Public Health, Department of Health Policy

Planning, and Management. P.O. Box, 7072, Kampala, Uganda

Full list of author information is available at the end of the article
}

Millennium Development Goal (MDG) in developing countries[4]. Uganda continues to have one of the highest maternal and child mortality worldwide, with an estimated Maternal Mortality Ratio (MMR) at 435/100,000 and child mortality at 137/1,000 live births [5]. The Ugandan government has prioritized reproductive health strategies which focus on accelerated reduction in maternal mortality and severe morbidity related to pregnancy and childbirth.

As early as 2001, the World Health Organization (WHO) established proven safe motherhood interventions that are required at household, community and facility levels to enable every pregnant woman to have a 
safe pregnancy and childbirth, and to provide couples with the best chance of having healthy infants [6]. The strategies include; providing skilled attendants to prevent, detect and manage the major obstetric complications, together with providing equipment, drugs and other supplies[7,8]. A few studies have found that facility interventions providing routine ANC have minimal beneficial effects to maternal health outcomes, creating a rationale for community-based interventions for pregnant women where educational and support programmes have been successful in increasing/improving skilled delivery, breastfeeding practices and postnatal attendance [9-12]. This reported success may be mainly attributable to spousal involvement, and not necessarily the community as a whole. Even though it is widely recognized that there is limited research on the role of male involvement during pregnancy [13-15], there are promising links to beneficial effects. Indeed some few prospective studies and literature reviews have successfully demonstrated that prenatal male involvement is associated with beneficial health outcomes such as; higher first trimester ANC visits, abstinence from smoking and alcohol consumption [14,16], and reduction in low birth-weight infants [14,17]. Evaluations of Prevention of Mother-to-Child Transmission of HIV (PMTCT) which is often implemented within the confines of safe motherhood have similarly shown male involvement to positively influence uptake of HIV testing and preventive interventions for vertical and sexual transmissions of HIV $[15,18,19]$.

Male attendance of skilled ANC is a fairly new field to research in Uganda. The available estimates depict a low attendance averaging 3\% in 2006 [20] but are based on health facility information systems that monitor male attendance in the PMTCT programme. Gulu district is located in northern Uganda, a region recovering from a 20-year-old insurgency. The civil war forced majority of its population into Internally Displaced Peoples' (IDP) camps. According to Gulu development plan (2007), the district has a maternal mortality ratio (MMR) of 700/ 100,000; infant mortality rate of 172/1,000 and ANC HIV sero-prevalence of $8.8 \%$ [21]. Gulu district MMR is similar to other districts in Northern Uganda with an MMR averaging 650/100,000 but, higher than neighbouring post-conflict affected Adjumani district in West Nile where the MMR is estimated at 550/100,000 [21]. In 2008, the district estimate for male attendance of skilled ANC was $18.4 \%$ having risen from about $3 \%$ in 2006 [22]. Of the total 23,408 pregnant women that were new ANC attendees in Gulu district in 2008, male attendance estimated at $18.4 \%$ varied by sub-county; $41.6 \%(1,107 / 2,746)$ in Aswa, 41.5\% $(2,529 / 6,264)$ in Omoro and only $5.0 \%$ $(660 / 14,398)$ in the Municipality[22]. The marked rise in male partner ANC attendance is possibly due to a robust district-wide PMTCT programme. This study assessed the level, perceived benefits and factors associated with male partner attendance of skilled ANC in a peri-urban community in Gulu.

\section{Methods}

\section{Study setting}

Gulu district is located in northern Uganda, with a population of 343,100 people [21] and approximately 17,155 (5\%) women expected to become pregnant annually. The annual population growth rate is $3.3 \%$ with a sex ratio of 95 males to 100 females [5]. The district health structure is made up of 48 health facilities, with about $77 \%$ (32) functional, most of which provide antenatal care services.

\section{Study design, participants and sampling procedure}

A cross-sectional survey design was used employing quantitative techniques. Study participants were male partners to women of reproductive age (18 - 49 years) that had a full-term delivery within the last 24 months preceding the study in Gulu district. Sample size was estimated using the modified Kish Leslie (1965) survey sampling formula with a $95 \%$ confidence interval, a precision of $5 \%$, an estimated proportion of male partners attending ANC of $18.4 \%$ and a conservative design effect of 1.5 to cater for intra-cluster variability[23]. The calculated sample size was 346 male respondents.

Omoro, one of the three counties in Gulu district was selected by simple random sampling. All parishes in the six sub-counties of Omoro (Odek, Lalogi, Lakwana, Bobi, Koro and Ongako) were listed. We selected 12 out of the total 28 parishes in all the sub-counties by simple random sampling. Consecutive recruitment of 29 participants in each cluster at parish level was done. The first participant was obtained from an eligible household along the primary road of the index cluster, which was located about 200 metres from the commercial focal point. The subsequent respondents were recruited by carrying out a door-to-door assessment of eligibility, along the primary, secondary and tertiary roads, up to $3 \mathrm{kms}$ away from the commercial focal point of the cluster. In the absence of an eligible respondent, the subsequent households were screened until a suitable respondent was found. In case of an eligible polygamous male partner, the information was asked about the wife that last delivered, irrespective of her rank. The process of identifying eligible respondents was continued until 29 participants were found in each cluster. On average, an eligible respondent was found from one in six households visited. Data were collected through face to face interviews using a pre-tested semi-structured questionnaire. 


\section{Data management and analysis}

The main outcome variable was male partner attendance of at least one skilled ANC visit of the spouse's last full-term pregnancy. Double data entry and validation was done in Epi data 3.1. Data was then exported to Stata 10.0 where frequencies and statistical analyzes were run. The outcome variable of the study [male attendance of ANC] was a binary categorical variable (attended, not attended). All independent variables had nearly same sample size as the outcome variable ( $\mathrm{n}=$ $331)$ with the highest item non response at $4.8 \%(16 /$ $331)$. Since the prevalence of the outcome was found to be high at $(65.4 \%)$, odds ratios were not a good approximation of the measure of association[24,25]. We computed Prevalence Risk Ratios (PRR) for association between the binary outcome [male partner attendance of at least one ANC visit, versus non-attendance], in relation to independent variables such as age and education level using GLM analysis with binomial family and a log link with robust standard errors $[24,25]$. All factors significant at $\mathrm{p}<0.15$ or potential confounders and socially plausible factors were included in the multivariable model to obtain adjusted PRR with their 95\% confidence intervals (95\%CI). Analysis was conducted using Stata version 10.0. We then did stepwise backward elimination until the best fitting model with a log likelihood tending toward zero was obtained. We identified statistically significant adjusted PRR from the model and reported them as independent factors associated with male attendance of skilled ANC.

\section{Ethical considerations}

The study obtained ethical approval from Makerere University School of Public Health (MUSPH) Higher Degrees and Ethical Committee. Written informed consent was obtained from adult respondents aged 18 years and above, clearly stating potential risks and benefits of the study and sought their voluntary participation.

\section{Results}

\section{Characteristics of study sample}

Table 1 shows the characteristics of male partners included in the study. A total of 331 adult male partners aged $\geq 18$ years were interviewed representing a response rate of $95.5 \%$. Nearly all respondents were household heads $99.1 \%(328 / 331)$, with a mean (SD) age of 31.9 $(\mathrm{SD}=8.2)$ years; range $18-62$ years. Out of the 331 respondents, majority were peasant farmers $(81.5 \%)$, most lived in rural areas (61.3\%), nearly all (97.9\%) were co-resident (staying together) with their female spouses. About $60.7 \%$ were religiously or traditionally married, and $17 \%$ were in polygamous marital unions.
Table 1 Characteristics of male respondents

\begin{tabular}{|c|c|c|}
\hline Variable & Freq $\mathrm{N}=331$ & Proportion (\%) \\
\hline \multicolumn{3}{|l|}{$\operatorname{Age}^{a}$} \\
\hline $15-24$ & 63 & 19 \\
\hline $25-34$ & 149 & 45 \\
\hline $35-44$ & 88 & 26.6 \\
\hline$\geq 45$ years & 31 & 9.4 \\
\hline \multicolumn{3}{|l|}{ School education } \\
\hline None & 12 & 3.7 \\
\hline Primary & 209 & 64.7 \\
\hline Secondary & 78 & 24.1 \\
\hline Tertiary & 23 & 7.1 \\
\hline Missing data & 8 & - \\
\hline \multicolumn{3}{|l|}{ Residence } \\
\hline Semi-urban & 201 & 61.3 \\
\hline Urban & 128 & 38.7 \\
\hline Missing data & 3 & - \\
\hline \multicolumn{3}{|l|}{ Household size $^{b}$} \\
\hline$\leq 4$ & 112 & 33.9 \\
\hline$>4$ & 218 & 66.1 \\
\hline Missing data & 1 & - \\
\hline \multicolumn{3}{|l|}{ Marital Status } \\
\hline Never married & 112 & 33.8 \\
\hline Married & 201 & 60.7 \\
\hline Living together & 17 & 5.1 \\
\hline Missing data & 1 & - \\
\hline \multicolumn{3}{|l|}{ Type of marriage } \\
\hline Monogamous & 273 & 83 \\
\hline Polygamous & 56 & 17 \\
\hline Missing data & 2 & - \\
\hline \multicolumn{3}{|l|}{ Religion } \\
\hline Protestant & 69 & 21 \\
\hline Catholic & 222 & 67.7 \\
\hline Other & 37 & 11.3 \\
\hline Missing data & 3 & - \\
\hline \multicolumn{3}{|l|}{ Occupation } \\
\hline Peasant farmer & 268 & 81.5 \\
\hline Manual & 20 & 6.1 \\
\hline Sales & 19 & 5.8 \\
\hline Professional & 22 & 6.7 \\
\hline Missing data & 3 & - \\
\hline \multicolumn{3}{|l|}{ No. of children } \\
\hline$\leq 3$ & 168 & 51.7 \\
\hline$>3$ & 157 & 48.3 \\
\hline Missing data & 6 & - \\
\hline
\end{tabular}

${ }^{\mathrm{a}}$ Mean age $31.9,{ }^{\mathrm{b}}$ Median household size $=5$ (IQR $4-8$ ), ${ }^{\mathrm{c}}$ Median no. of children $=3($ IQR $2-5)$.

\section{Level of male attendance of ANC, knowledge and perceptions}

Respondents were asked whether or not they attended ANC with their spouses during their last full-term pregnancy, what they knew about ANC services offered, 
their willingness to attend ANC in subsequent pregnancies, and what they perceived as benefits and barriers of attendance. The proportion of male partners that participated in at least one ANC visit was $65.4 \%$ (95\%CI $60.3,70.5)$. Their willingness to attend subsequent ANC visits with their spouses was also high, 93.7\% (95\%CI 91.1, 96.3). Most men attended no more than two ANC visits $(60.5 \%)$, but this attendance was more common at government health facilities compared to other facilities, $(82.5 \%$ vs $17.5 \%, \mathrm{p}<0.001)$. The ANC visits were mostly begun during the spouse's first trimester (59.8\%).

About 96\% (318 out of 331) respondents regarded attendance of spousal ANC as beneficial. The major perceived benefits of attending ANC were HIV screening (74.5\%), monitoring foetal growth (34\%), and identifying complications in pregnancy (18.9\%). Male partners' knowledge about ANC services offered was limited; about half, 49.9\% (164/329) could correctly mention two or fewer services offered, 47.1\% (155/329) mentioned 3 5 services, and only $3 \%(10 / 329)$ mentioned at least five services offered.

The main barriers to attendance of ANC identified by male partners were: long waiting time $(41.7 \%)$, lack of transport means (35.8\%), walking distance greater than one hour to a health facility (34.1\%) and fear of being tested for HIV (29.7\%). Other barriers reported include; non-invitation, attaching no importance to their attendance and having a concurrent task or job demand at the same time as the spouse's ANC visit.

\section{Factors associated with male attendance of ANC}

Table 2 shows bivariate analysis of factors associated with male attendance of skilled ANC. The attendance rate was about 3 times higher among male partners that could identify at least three services offered at ANC compared to those identifying two or less services, (PRR 2.72; 95\%CI 2.20, 3.36; $\mathrm{p}<0.001$ ). Also, the attendance rate was significantly higher if the spouse's last delivery took place in a health facility compared to those where the last delivery occurred either at home or at a traditional birth attendant's place, (PRR 1.42; 95\%CI 1.08, $1.88 ; \mathrm{p}=0.012$ ), or if the male was religiously/traditionally married compared to consensual marital unions (PRR 1.26; 95\%CI 1.04, 1.52; $\mathrm{p}=0.014$ ). Other factors associated with higher male attendance were attainment of secondary or higher level education (PRR 1.25; 95\%CI $1.08-1.46 ; \mathrm{p}=0.003$ ), and perception of foetal monitoring as being a benefit of attendance (PRR 1.20; 95\% CI 1.03, 1.40; $\mathrm{p}=0.018$ ).

On the other hand, attendance was significantly lower if the source of health information were community campaigns (PRR 0.67; 95\%CI 0.51, 0.88; $\mathrm{p}=0.005$ ) or if female spouse's last full term pregnancy was more than one year ago (PRR 0.77; 95\%CI 0.65, 0.91; $\mathrm{p}=0.003$ ).

\section{Multivariable analysis}

After adjusting for confounding in a multivariable analysis, shown in Table 3, the factors that remained significantly associated with male attendance of ANC were: knowledge of at least 3 services offered at ANC (adj. PRR 2.77; 95\%CI 2.24, 3.42; $\mathrm{p}<0.001$ ), last delivery was at a health facility (adj.PRR 1.31; 95\%CI 1.04, 1.64; $\mathrm{p}=$ 0.020 ) and having a health facility worker as the source of health information (adj.PRR 1.14; 95\%CI 1.01, 1.29; $\mathrm{p}=0.023$ ). Conversely, factors significantly associated with lower attendance rate were: long distance to nearest health facility (at least $5 \mathrm{KM}$ ) or longer than one hour's walk (adj.PRR 0.83, 95\%CI 0.70, 0.98; $\mathrm{p}=0.034$ ), or if male intended female spouse to carry another pregnancy (adj.PRR 0.83; 95\%CI 0.71, 0.97; $\mathrm{p}=0.023$ ).

\section{Discussion}

In this study, the level of male attendance of skilled ANC was relatively high at $65.4 \%(60.3-70.5)$ as compared to $42 \%$ for Omoro county in Gulu observed from district health management information system (HMIS) reports in 2008 [22] and much higher than the $4 \%$ national average [20]. This study reports relatively high levels of male attendance of ANC possibly because the sample was composed of peri-urban males who arguably have better access to health facilities where integrated ANC/PMTCT services are provided than the rural that make up the majority of the population. Studies in SubSaharan localities where PMTCT programmes are being implemented as part of the ANC services report male attendance rates at $12.5 \%$ in northern Tanzania [26], about 15 and $16 \%$ respectively at different clinics in Nairobi, Kenya [15,27] and 25\% in Côte d'Ivoire[19].

HIV screening was perceived as the main benefit to ANC attendance. Although it was not significantly associated with male partner ANC attendance, it is of public health importance because HIV screening is one of the quality services offered at ANC $[2,20]$. Furthermore HIV testing is meant to benefit the couple so that assessment of the risk of HIV infection to the unborn child is done during pregnancy and prevented. In case of couples that are HIV discordant, male attendance presents the opportunity for health providers to promote use of barrier contraceptive methods such as condoms. The perceived benefit to male partners of monitoring foetal growth is similarly of public health importance, even though it was not found significantly associated with male attendance of ANC. A study conducted in Taiwan reported anxiety of the male partner about the newborn during the wife's pregnancy to increase their participation in maternal health care [28]. Perceived benefit of foetal monitoring during spousal pregnancy is worth inclusion in subsequent studies to determine whether it is a predictor of male attendance of maternal health care. 
Table 2 Bivariable analysis of independent variables associated with male attendance of skilled ANC

\begin{tabular}{|c|c|c|c|c|c|}
\hline \multirow[t]{2}{*}{ Independent Variabl } & \multirow[b]{2}{*}{ Attended Freq, $\mathrm{N}=331(\%)$} & \multirow[b]{2}{*}{ Total } & \multicolumn{2}{|c|}{ Unadjusted } & \multirow[b]{2}{*}{ p-value } \\
\hline & & & PRR & $(95 \% \mathrm{Cl})$ & \\
\hline \multicolumn{6}{|l|}{ Age } \\
\hline $15-24$ & $41(65.0)$ & 63 & 1 & & \\
\hline $25-34$ & $94(63.9)$ & 147 & 0.98 & $(1.78-1.22)$ & 0.875 \\
\hline $35-44$ & $58(65.9)$ & 88 & 1.01 & $(0.80-1.28)$ & 0.916 \\
\hline$\geq 45$ & $22(70.9)$ & 31 & 1.09 & $(0.81-1.45)$ & 0.557 \\
\hline \multicolumn{6}{|l|}{ School education } \\
\hline$\leq$ Primary & 133(62.1) & 214 & 1 & & \\
\hline$\geq$ Secondary & $78(76.4)$ & 102 & 1.25 & $(1.08-1.46)$ & $0.003^{* *}$ \\
\hline \multicolumn{6}{|l|}{ Residence } \\
\hline Semi-urban & $131(65.5)$ & 200 & 1 & & \\
\hline Urban & $83(65.8)$ & 126 & 1.00 & $(0.86-1.18)$ & 0.945 \\
\hline \multicolumn{6}{|l|}{ Household size } \\
\hline$\leq 4$ & $72(64.2)$ & 112 & 1 & & \\
\hline$>4$ & $142(65.7)$ & 216 & 1.02 & $(0.86-1.21)$ & 0.795 \\
\hline \multicolumn{6}{|l|}{ Marital status } \\
\hline Never married & $63(56.2)$ & 112 & 1 & & \\
\hline Married & $142(71.0)$ & 200 & 1.26 & $(1.04-1.52)$ & $0.014^{*}$ \\
\hline Not married & 10(58.8) & 17 & 1.04 & $(0.67-1.60)$ & 0.839 \\
\hline \multicolumn{6}{|l|}{ Type of marriage } \\
\hline Monogamous & $182(66.9)$ & 272 & 1 & & \\
\hline Polygamous & $33(60.0)$ & 55 & 0.89 & $(0.71-1.13)$ & 0.356 \\
\hline \multicolumn{6}{|l|}{ Occupation } \\
\hline Manual worker & 185(64.6) & 286 & 1 & & \\
\hline Sales & $15(78.9)$ & 19 & 1.22 & $(0.95-1.56)$ & 0.115 \\
\hline Professional $^{\mathrm{a}}$ & $14(63.6)$ & 22 & 0.98 & $(0.70-1.36)$ & 0.922 \\
\hline \multicolumn{6}{|c|}{ Reported distance to nearest health facility } \\
\hline$\leq 5 \mathrm{KM}$ & $178(67.7)$ & 263 & 1 & & \\
\hline$>5 \mathrm{KM}$ & $37(56.0)$ & 66 & 0.82 & $(0.65-1.04)$ & 0.108 \\
\hline \multicolumn{6}{|c|}{ Main sources of health information } \\
\hline \multicolumn{6}{|l|}{ Radio } \\
\hline No & $47(22.1)$ & 75 & 1 & & \\
\hline Yes & 166(77.9) & 252 & 1.05 & $(0.86-1.27)$ & 0.618 \\
\hline \multicolumn{6}{|l|}{ VHT member } \\
\hline No & 136(63.8) & 218 & 1 & & \\
\hline Yes & $77(36.2)$ & 109 & 1.13 & $(0.96-1.32)$ & 0.126 \\
\hline \multicolumn{6}{|c|}{ Health worker at facility } \\
\hline No & $115(54.0)$ & 189 & 1 & & \\
\hline Yes & $98(46.0)$ & 138 & 1.16 & $(0.99-1.36)$ & 0.053 \\
\hline \multicolumn{6}{|c|}{ Community campaign } \\
\hline No & 183(85.9) & 263 & 1 & & \\
\hline Yes & $30(14.1)$ & 64 & 0.67 & $(0.51-0.88)$ & $0.005^{* *}$ \\
\hline \multicolumn{6}{|c|}{ Knowledge about services offered at ANC } \\
\hline$\leq 2$ services & $57(35.2)$ & 162 & 1 & & \\
\hline 3-5 services & 158(95.8) & 165 & 2.72 & $(2.20-3.36)$ & $0.000^{* * *}$ \\
\hline \multicolumn{6}{|c|}{ Duration since spouse last carried complete pregnancy } \\
\hline$\leq 1$ year & $38(80.9)$ & 47 & 1 & & \\
\hline$>1$ year & $177(62.8)$ & 282 & 0.77 & $(0.65-0.91)$ & $0.003^{* *}$ \\
\hline Last delivery of sp & health facility & & & & \\
\hline No & $28(48.3)$ & 58 & 1 & & \\
\hline Yes & $187(69.0)$ & 271 & 1.42 & $(1.08-1.88)$ & $0.012^{*}$ \\
\hline
\end{tabular}


Table 2 Bivariable analysis of independent variables associated with male attendance of skilled ANC (Continued) Intends spouse to carry another pregnancy

$\begin{array}{ll}\text { No } & 35(76.1) \\ \text { Yes } & 177(63.7)\end{array}$

$177(63.7)$

46

276

Would attend ANC in subsequent pregnancy

$\begin{array}{ll}\text { No } & \text { 09(4.3) } \\ \text { Yes } & \text { 199(95.7) }\end{array}$

199(95.7)

Monitoring Feotal growth as perceived benefit

$\begin{array}{ll}\text { No } & 131(62.4) \\ \text { Yes } & 79(37.6)\end{array}$

$$
\text { 79(37.6) }
$$

20

295

209

107

199

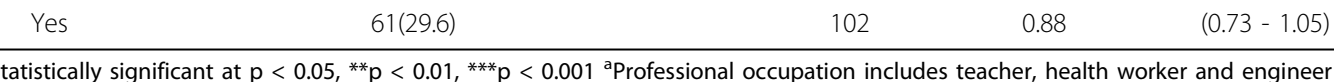

145(70.4)

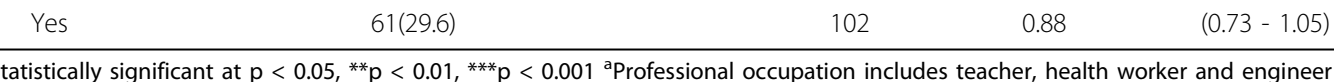

1

0.83

$(0.69-1.00)$

0.059

1

1.43

1.43

$(0.99-2.06)$

0.054

$209-1$

1.20

$(1.03-1.40)$

$0.018^{*}$

Walking distance $>1$ hour to health facility as perceived barrier

Statistically significant at $\mathrm{p}<0.05, * * \mathrm{p}<0.01, * * \mathrm{p}<0.001$ a Professional occupation includes teacher, health worker and engineer

Table 3 Multivariable analysis of factors associated with male attendance of skilled ANC

\begin{tabular}{|c|c|c|c|c|}
\hline \multicolumn{5}{|c|}{ OUTCOME: Male Attendance of skilled ANC } \\
\hline & Attended & & & \\
\hline & Freq, $N=331(\%)$ & & & \\
\hline \multirow[t]{2}{*}{ Independent Variable } & & & Unadjusted $(95 \% \mathrm{Cl})$ & Adjusted $(95 \% \mathrm{Cl})$ \\
\hline & & & PRR & PRR \\
\hline \multicolumn{5}{|l|}{ Age } \\
\hline $15-24$ & $41(65.0)$ & 63 & 1 & 1 \\
\hline $25-34$ & $94(63.9)$ & 147 & $0.98(1.78-1.22)$ & $0.91(0.75-1.11)$ \\
\hline $35-44$ & $58(65.9)$ & 88 & $1.01(0.80-1.28)$ & $0.93(0.75-1.17)$ \\
\hline$\geq 45$ & $22(70.9)$ & 31 & $1.09(0.81-1.45)$ & $0.84(0.66-1.08)$ \\
\hline \multicolumn{5}{|l|}{ Marital status } \\
\hline Never married & $63(56.2)$ & 112 & 1 & 1 \\
\hline Married & 142(71.0) & 200 & $1.26(1.04-1.52)^{*}$ & $1.11(0.95-1.30)$ \\
\hline Not married & $10(58.8)$ & 17 & $1.04(0.67-1.60)$ & $0.98(0.75-1.30)$ \\
\hline \multicolumn{5}{|l|}{ Type of marriage } \\
\hline Monogamous & $182(66.9)$ & 272 & 1 & 1 \\
\hline Polygamous & $33(60.0)$ & 55 & $0.89(0.71-1.13)$ & $0.86(0.74-1.00)$ \\
\hline \multicolumn{5}{|c|}{ Reported distance to nearest health facility } \\
\hline$\leq 5 \mathrm{KM}$ & $178(67.7)$ & 263 & 1 & 1 \\
\hline$>5 \mathrm{KM}$ & $37(56.0)$ & 66 & $0.82(0.65-1.04)$ & $0.83(0.70-0.98)^{*}$ \\
\hline \multicolumn{5}{|c|}{ Knowledgeable of ANC services } \\
\hline$\leq 2$ services & $57(35.2)$ & 162 & 1 & 1 \\
\hline$\geq 3$ services & 158(95.8) & 165 & $2.72(2.20-3.36)^{* * *}$ & $2.77(2.24-3.42)^{* * *}$ \\
\hline \multicolumn{5}{|c|}{ Intends spouse to carry another pregnancy } \\
\hline No & $35(76.1)$ & 46 & 1 & \\
\hline Yes & $177(63.7)$ & 276 & $0.83(0.69-1.00)$ & $0.83(0.71-0.97)^{*}$ \\
\hline \multicolumn{5}{|c|}{ Health information mainly obtained from health facility worker } \\
\hline No & $115(54.0)$ & 189 & 1 & \\
\hline Yes & $98(46.0)$ & 138 & $1.16(0.99-1.36)$ & $1.14(1.01-1.29)^{*}$ \\
\hline \multicolumn{5}{|c|}{ Last delivery of spouse was at health facility } \\
\hline No & $28(48.3)$ & 58 & 1 & \\
\hline Yes & $187(69.0)$ & 271 & $1.42(1.08-1.88)^{*}$ & $1.31(1.04-1.64)^{*}$ \\
\hline
\end{tabular}

log likelihood $=-270.43$

${ }^{*} \mathrm{p}<0.05,{ }^{* *} \mathrm{p}<0.01{ }^{* * *} \mathrm{p}<0.001$ 
The main factors identified by the respondents in the survey as barriers to attendance of ANC were lack of transportation, long waiting time and long walking distance to a health facility. Perceiving the walking distance to the health facility as long (greater than one-hour walk or greater than $5 \mathrm{~km}$ ) was a prominent barrier and associated with reduced male attendance of ANC $(p=0.034)$. Long distance as a barrier to male attendance of maternal health care has been reported by other cross-sectional studies in Tanzania, Uganda and Bangladesh [29-31]. This finding emphasizes the need for the health sector to further increase access to maternal health services.

On the other hand, males that wanted their spouses to carry another pregnancy were found to be associated with reduced attendance of ANC. This finding could suggest that fertility preferences are modified once a man attends ANC with the spouse during pregnancy. This is possible because health education about family planning which is provided during the pre and postnatal visits encourages child spacing for at least two years[8]. We however also found that male partners with high fertility preferences were less likely to have four or more children, implying that they wanted to have more children because they perceived the number they had as few. Given that total fertility rate in Uganda is $6.7 \%[5,32]$, the latter may be the alternative explanation for this finding.

Interestingly, we found that male attendance of ANC was associated with higher likelihood of spouse having skilled delivery at her last childbirth. To the best of our knowledge, this is a new finding; however, some community-level intervention studies found health education and support programmes to increase skilled attendance at childbirth [9-12].

Knowledge about safe motherhood services among the male partners was limited. Only $47.1 \%$ respondents knew 3 - 5 services offered at ANC. This finding is consistent with other studies in Taiwan, India and Tanzania where male partners were found to have limited knowledge about safe motherhood and sexuality [28,33-36]. In Uganda, this finding is not surprising because male attendance of safe motherhood is a new approach that was introduced with the national PMTCT program in 2001 [20]. Limited knowledge of male partners about maternal health issues has been reported to be a significant barrier to their attendance [34,37]. In this study, male partners that had reasonable knowledge of services offered at ANC (at least three services) were significantly more likely to attend ANC ( $<<0.001)$. This finding supports the evidence that increasing male partner's knowledge of safe motherhood is positively associated with attendance of ANC [38]. However, the study design does not allow us to conclusively affirm the temporal relation between knowledge and ANC attendance. It is also possible that the more one attends $\mathrm{ANC}$, the more knowledgeable one becomes about ANC services.

Obtaining health information from a facility health worker was positively associated with male partner attendance of ANC with their spouses. The finding suggests that males regard health workers as a credible source of health information, and this is influential on their health behaviour. This finding supports evidence from a systematic review by Sternberg et al (2004) that concluded; health promotion for male involvement in sexual and reproductive health programs has a high promise of success [34]. The alternative explanation to this finding is that male attendance of ANC was positively associated with obtaining health information from facility health workers, which would point towards effectiveness of health education at ANC[38].

We found that male partner's education was not significantly associated with attendance of ANC in the adjusted analysis. The interpretation of this result is that the variable is collinear with knowledge of ANC services, and we therefore omit it from the final model. A cross-sectional study conducted in Nigeria [39] that interviewed pregnant women, who are considered surrogate respondents in this comparison, showed that low education was associated with reduced utilization of ANC similar to other studies [30,31].

\section{Study Limitations}

Recall bias could have been present even after restricting inclusion to males whose spouses last delivered 24 months prior to the survey. Two years is a long period, yet pregnancy may not signify as much importance to the male partner as it does to the female. Additionally reporting bias arising from men wanting to provide socially desirable responses especially regarding the level of ANC attendance could have been a potential pitfall to the study. This could have been overcome by cross validation of the men's responses by women interviews.

In this study, we used multi-stage cluster sampling but analyzed subjects at individual level, which could have potentially reduced the statistical efficiency at analysis [40]. We used a conservative design effect of 1.5 to cater for the sampling error, but this may not have been sufficient[40].

Our study population was largely peri-urban, therefore our findings may not be entirely generalizable to the rest of Gulu district and other rural settings in Uganda. However, we gain insights into how similar populations can be targeted to improve male ANC attendance.

This study design was cross-sectional which limits us from making any causal inferences in relation to the main outcome and independent variables. 


\section{Conclusions}

Male attendance of skilled ANC of a peri-urban population in Gulu was high at $65.4 \%$ compared to $42 \%$ in the rest of the district and an estimated $10 \%$ attendance rate in the other regions in Uganda. Willingness to attend subsequent skilled ANC was nearly universal. Male partners had favourable perceptions for attendance of skilled ANC that included foetal growth monitoring, HIV screening and identifying complications during pregnancy.

Factors associated with male attendance of ANC were: knowledge of at least three ANC services, obtaining health information from facility health workers, wife last gave birth at a health facility, distance to nearest health facility less than 1 hour or $5 \mathrm{~km}$ and the male partner having no intention for the spouse to carry another pregnancy.

Knowledge about ANC services was the main independent variable associated with male attendance of ANC with their spouses. We recommend that governments and local health authorities should develop strategies to empower men (both in communities and at health facilities) with knowledge about ANC. Such strategies may contribute to increasing male attendance in ANC, improve skilled attendance at delivery and improve maternal health outcomes. Strategies that increase male attendance of skilled ANC are likely to be feasible in post-conflict regions and resource limited settings.

\footnotetext{
Acknowledgements

We thank the respondents of the study for their time and information that have enabled us gain better insight into male attendance of spousal ANC. We also extend our appreciation to Dr. Onek Awil, district health officer and the district health team members in Gulu particularly; Ojok Naphtali, Nyeko Gaudensio, Akot Amos Tala, Amal Milly, Ocan Robert and Okello Peter who participated in data collection and translation of tools for this study. We specially thank Dr. Fredrick Makumbi at Makerere School of Public Health, Uganda who guided and reviewed the analysis of this study. We also acknowledge his useful comments to the manuscript.

This study was supported by a Belgian Government Scholarship for the Master of Public Health education program Ref: UNI2007/07 Scholarship number L07UGA079.
}

\section{Author details \\ ${ }^{1}$ Makerere University School of Public Health, Department of Health Policy Planning, and Management. P.O. Box, 7072, Kampala, Uganda. ${ }^{2}$ Makerere University School of Public Health, Department of Epidemiology and, Biostatistics, P.O.Box, 7072, Kampala, Uganda.}

\section{Authors' contributions}

RT: Designed the study, coordinated recruitment of participants, collected and entered data, analyzed data and drafted the manuscript. JNS: Designed the study, participated in data analysis and reviewed all drafts of the manuscript. JKL: Designed the study, participated in data analysis, reviewed all drafts of the manuscript. NTM: Guided data analysis, reviewed all drafts of the manuscript. All authors read and approved the final manuscript.

\section{Competing interests}

The authors declare that they have no competing interests.

Received: 1 February 2010 Accepted: 16 September 2010 Published: 16 September 2010
References

1. de Bernis L, Sherratt DR, AbouZahr C, Van Lerberghe W: Skilled attendants for pregnancy, childbirth and postnatal care. Br Med Bull 2003, 67:39-57.

2. WHO: Maternal Mortality in 2005. Estimates developed by WHO, UNICEF, UNFPA and the World Bank. World Health Organization: Geneva 2007.

3. UNICEF: Progress for Children. A report card on maternal mortality No.7. United Nations Children's Fund 2008.

4. AbouZahr C: Safe motherhood: a brief history of the global movement 1947-2002. Br Med Bull 2003, 67:13-25.

5. UBOS: Uganda Demographic and Health Survey. 2006. Uganda Bureau of Statistics (UBOS) and Macro International Inc. Calverton, Maryland, USA 2007.

6. Portela A, Santarelli C: Empowerment of women, men, families and communities: true partners for improving maternal and newborn health. Br Med Bull 2003, 67:59-72.

7. WHO: Making pregnancy safer: the critical role of the skilled attendant A joint statement by WHO, ICM and FIGO. Department of Reproductive Health and Research World Health Organization: Geneva 2004.

8. MoH: The National Policy Guidelines and Service Standards for Sexual and Reproductive Health and Rights. 2006.

9. Belizan JM, Barros F, Langer A, Farnot U, Victora C, Villar J: Impact of health education during pregnancy on behavior and utilization of health resources. Latin American Network for Perinatal and Reproductive Research. Am J Obstet Gynecol 1995, 173:894-9.

10. Hounton S, Byass P, Brahima B: Towards reduction of maternal and perinatal mortality in rural Burkina Faso: communities are not empty vessels. Glob Health Action 2009, 2.

11. Mushi D, Mpembeni R, Jahn A: Effectiveness of community based safe motherhood promoters in improving the utilization of obstetric care. The case of Mtwara Rural District in Tanzania. BMC Pregnancy Childbirth 10:14.

12. Turan JM, Say L: Community-based antenatal education in Istanbul, Turkey: effects on health behaviours. Health Policy Plan 2003, 18:391-8.

13. Roth DM, Mbizvo MT: Promoting safe motherhood in the community: the case for strategies that include men. Afr J Reprod Health 2001, 5:10-21.

14. Alio AP, Salihu HM, Kornosky JL, Richman AM, Marty PJ: Feto-infant Health and Survival: Does Paternal Involvement Matter? Matern Child Health J 2009.

15. Katz DA, Kiarie JN, John-Stewart GC, Richardson BA, John FN, Farquhar C: Male perspectives on incorporating men into antenatal HIV counseling and testing. PLoS One 2009, 4:e7602.

16. Martin LT, McNamara MJ, Milot AS, Halle T, Hair EC: The effects of father involvement during pregnancy on receipt of prenatal care and maternal smoking. Matern Child Health J 2007, 11:595-602.

17. Hohmann-Marriott B: The couple context of pregnancy and its effects on prenatal care and birth outcomes. Matern Child Health J 2009, 13:745-54.

18. Welty TK, Bulterys M, Welty ER, Tih PM, Ndikintum G, Nkuoh G, Nkfusai J, Kayita J, Nkengasong JN, Wilfert CM: Integrating prevention of mother-tochild HIV transmission into routine antenatal care: the key to program expansion in Cameroon. J Acquir Immune Defic Syndr 2005, 40:486-93.

19. Orne-Gliemann J, Desgrees-Du-Lou A: The involvement of men within prenatal HIV counselling and testing. Facts, constraints and hopes. AIDS 2008, 22:2555-7.

20. $\mathrm{MoH}$ : National Guidelines for Prevention of mother-to-child transmission of HIV. 2006.

21. Gulu: Gulu District Development Plan 2007/08 - 2009/10. Gulu 2007.

22. Gulu: Prevention of Mother-to-child transmission of HIV (PMTCT) reports. Gulu 2008.

23. Kish L, ed: Survey Sampling. John Wiley and Sons, Inc: New York 1965.

24. Spiegelman D, Hertzmark E: Easy SAS calculations for risk or prevalence ratios and differences. Am J Epidemiol 2005, 162:199-200.

25. Schmidt $\mathrm{CO}$, Kohlmann $\mathrm{T}$ : When to use the odds ratio or the relative risk? Int J Public Health 2008, 53:165-7.

26. Msuya SE, Mbizvo EM, Hussain A, Uriyo J, Sam NE, Stray-Pedersen B: Low male partner participation in antenatal HIV counselling and testing in northern Tanzania: implications for preventive programs. AIDS Care 2008, 20:700-9.

27. Farquhar C, Kiarie JN, Richardson BA, Kabura MN, John FN, Nduati RW, Mbori-Ngacha DA, John-Stewart GC: Antenatal couple counseling increases uptake of interventions to prevent HIV-1 transmission. J Acquir Immune Defic Syndr 2004, 37:1620-6. 
28. Hung $\mathrm{CH}$, Chung HH, Liu YH: [Correlates of couples' attitudes toward husband's childbirth participation]. Kaohsiung J Med Sci 1997, 13:360-9.

29. Mrisho M, Schellenberg JA, Mushi AK, Obrist B, Mshinda H, Tanner M, Schellenberg D: Factors affecting home delivery in rural Tanzania. Trop Med Int Health 2007, 12:862-72.

30. Tann CJ, Kizza M, Morison L, Mabey D, Muwanga M, Grosskurth H Elliott AM: Use of antenatal services and delivery care in Entebbe, Uganda: a community survey. BMC Pregnancy Childbirth 2007, 7:23.

31. Anwar I, Sami M, Akhtar N, Chowdhury ME, Salma U, Rahman M, Koblinsky M: Inequity in maternal health-care services: evidence from home-based skilled-birth-attendant programmes in Bangladesh. Bull World Health Organ 2008, 86:252-9.

32. AbouZahr C: Maternal and perinatal health. In Health dimensions of sex and reproduction. Global burden of Disease and Injury series Edited by: Murray CJL, Lopez AD 1998, III:111-164.

33. Singh KK, Bloom SS, Tsui AO: Husband's reproductive health knowledge, attitudes and behaviour in Uttah, Pradesh, India. Stud Fam Plann 1998, 29:388-399.

34. Sternberg $P$, Hubley J: Evaluating men's involvement as a strategy in sexual and reproductive health promotion. Health Promot Int 2004, 19:389-96

35. Mullany BC: Barriers to and attitudes towards promoting husbands' involvement in maternal health in Katmandu, Nepal. Soc Sci Med 2006, 62:2798-809

36. Theuring S, Mbezi P, Luvanda H, Jordan-Harder B, Kunz A, Harms G: Male involvement in PMTCT services in Mbeya Region, Tanzania. AIDS Behav 2009, 13(Suppl 1):92-102.

37. Dutta M, Kapilashrami MC, Tiwari VK: Knowledge, awareness and extent of male participation in key areas of reproductive health and child health in urban slums of Delhi. Health and Population Perspectives and Issues 2004, 27:49-66.

38. Mullany BC, Becker S, Hindin MJ: The impact of including husbands in antenatal health education services on maternal health practices in urban Nepal: results from a randomized controlled trial. Health Educ Res 2007, 22:166-76.

39. Olayemi O, Bello FA, Aimakhu CO, Obajimi GO, Adekunle AO: Male Participation in Pregnancy and Delivery in Nigeria: A Survey of Antenatal Attendees. J Biosoc Sci 2009, 1-11.

40. Killip S, Mahfoud Z, Pearce K: What is an intracluster correlation coefficient? Crucial concepts for primary care researchers. Ann Fam Med 2004, 2:204-8.

\section{Pre-publication history}

The pre-publication history for this paper can be accessed here: http://www.biomedcentral.com/1471-2393/10/53/prepub

doi:10.1186/1471-2393-10-53

Cite this article as: Tweheyo et al:: Male partner attendance of skilled antenatal care in peri-urban Gulu district, Northern Uganda. BMC Pregnancy and Childbirth 2010 10:53.

\section{Submit your next manuscript to BioMed Central and take full advantage of:}

- Convenient online submission

- Thorough peer review

- No space constraints or color figure charges

- Immediate publication on acceptance

- Inclusion in PubMed, CAS, Scopus and Google Scholar

- Research which is freely available for redistribution

Submit your manuscript at www.biomedcentral.com/submit 